\title{
Mechanical Properties of Structural Light Weight Concrete by Blending Cinder \& LECA
}

\author{
Anil Kumar $\mathbf{R}^{1}$, Dr.P.Prakash ${ }^{2}$ \\ Assistant Professor, Department of Civil Engineering, MSRIT, Bangalore, India ${ }^{1}$ \\ Professor \& HOD, Department of CTM, DSCE, Bangalore, India ${ }^{2}$
}

\begin{abstract}
This document gives formatting instructions for authors preparing papers for publication in the Proceedings of an International Journal. The authors must follow the instructions given in the document for the papers to be published. You can use this document as both an instruction set and as a template into which you can type your own text. The experimental work carried out aims to study on the strength properties of structural light weight concrete produced replacing coarse aggregate by blending light weight aggregates such as Cinder and Leca for M30 grade of concrete. The light weight aggregates such as Cinder and Leca were blended in various percentage proportions 0:100, 10:90, 20:80; 30:70; 40:60, 50:50 and vice-versa by volume of concrete to prepare light weight concrete. The properties such as compressive strength, split tensile strength and density are studied by casting 33 no. of plain cube specimens of size $150 \times 150 \times 150 \mathrm{~mm}$ and cylindrical moulds of $150 \times 300 \mathrm{~mm}$. M30 grade light weight concrete with $60 \%$ Cinder and Leca $40 \%$ had an average compressive strength of $36.52 \mathrm{~N} / \mathrm{mm} 2$ and split tensile strength of $2.5 \mathrm{~N} / \mathrm{mm} 2$. Addition of Ground Granulated Blast Furnace Slag (GGBFS) is used by replacing 20\% of cement which enhanced the compressive strength to $39.20 \mathrm{~N} / \mathrm{mm} 2$.
\end{abstract}

Keywords: Compressive strength, Cinder, Leca, Split tensile strength, Density, GGBFS.

\section{INTRODUCTION}

Concrete is considered to be composite material which is a mixture of mortar and coarse aggregate, the former acts as matrix of binder material and the later becomes the rigid filler material. For normal weight concrete (NWC), since the coarse aggregate possesses a larger value of $\mathrm{E}$ value, therefore it behaves as the major supporting material. The mortar, on other hand, can only be treated as a medium for stress transfer. For Lightweight Aggregate Concrete (LWC), however, the aggregate becomes the minor supporting part since it normally possesses a smaller young's modulus value. Fractures will be found in the aggregate portion and the concrete strength is mainly dependent on the particle and packing strengths of coarse lightweight aggregate.

Theoretically, the achievable strength of concrete can be determined by mortar strength and the particle strength of coarse aggregate. In fact, however, the coarse aggregate in concrete is not uniform and contains various grain sizes based on the gradation curve. It is improper to access the LWC strength according to the particle strength of a single aggregate. Instead the "packing strength", being the part of the LWAC strength contributed by the pack of the group of LWA's, is considered more representative. Lightweight concrete has been widely used in wall panels, masonry blocks, roof decks, and precast concrete units in many building applications.

There are many advantageous qualities of lightweight concrete, such as its low density, low thermal conductivity, reduction of dead load, fast building rate, and low haulage cost. Lightweight concrete (LWC) has been successfully used since the ancient Roman times and it has gained its popularity due to its lower density and superior thermal insulation properties Compared with normal weight concrete (NWC), LWC can significantly reduce the dead load of structural elements, which makes it especially attractive in multi-storey buildings.

Lightweight aggregate concrete (LWC) has been used as a construction material for many decades. The main objective for using LWAC is normally to reduce cost by reducing the dead load of structures. E.g. with low weight the dimensions of the foundations in buildings can be reduced in areas with low bearing capacities, the inertia actions are reduced in seismic regions and it enables easier handling and transportation of precast elements. Even with the major advantage of reduced weight and the high strength-to-weight ratio of the material compared to conventional concrete. Other advantages of LWC compared to normal weight concrete are the improved durability properties, fire resistance and the low thermal conductivity.

The use of light weight aggregates concrete in structures offers many advantages over the conventional normal weight concrete, including an increased strength weight ratio and improved thermal and sound insulation and fire resistances properties [K.Dhir and et.al,1984]. In concrete construction field, the concrete represents a very large proportion of the total load on the structure and there are clearly considerable advantages in reducing its density. One of the ways to reduce the weight of a structure is the use of light weight aggregate concrete [Mouli and Khelali 2008]. Light weight aggregate concrete (LWAC) has been used successfully for structural purposes for many years, because of their improved properties such as the workability, strength, less dead load and resistance to 
freezing and thawing of light weight concrete [V. Khonsari and et.al 2010].

The advancement in the new construction materials has lead to develop high strength materials, which are generally selected to reduce the weight of the construction. Also the developments in the stress analysis methods enable a more reliable determination of local stresses in the materials, which permit safety factors to be reduced resulting in further weight savings [Dr. V Bhaskar Desai and et.al 2014]

Structural lightweight concrete has been widely used following advances in production technology for lightweight aggregates. The advantage of lightweight concrete is reduced dead load for structures. Thus, the required cross-section of columns, amount of steel, and foundation load can decrease, given that lightweight concrete has acceptable performance in terms of strength [Jin Young Yoon and et.al 2015].

The aim of experiment is to develop the light weight concrete for the mix design of conventional concrete such as M30 by full replacement of the portion of coarse aggregates (granite) by blending of light weight aggregates such as CINDER \& LECA with different percentages \& thereby achieving the target strength with low density of concrete. The concrete which is thus developed is then compared with the conventional M30 grade concrete \& further the graphs are obtained for the above comparison.

\section{CHARACTERIZATION OF LIGHT WEIGHT AGGREGATES}

In this study, the materials used are

Cement-Ordinary Portland cement 43 grade confirming to IS 12269-1987.

Fine aggregates - Confirming to zone II passing through $4.75 \mathrm{~mm}$ IS sieve.

Coarse aggregates - Locally available granites passing through $20 \mathrm{~mm}$ IS sieve are used.

Light weight aggregates used in experimentation- In this study LECA and Cinder was selected as light weight aggregates to replace natural aggregates in concrete. Before deciding any material to be used as aggregate it has to possess some standards set by IS: 1343 . As we are concerned with the mix design the basic tests were conducted the results were determined.

CINDER: Cinder is a naturally occurring light weight rock of igneous origin. It is a pyroclastic material which is similar to that of pumice and has many cavities with low density which can float in water. Cinder is generally black, brown or red in color depending on its chemical composition. Now a days it is also called by name Scoria.

Volcanic cinders are uncemented, vitric, have bubble-like cavities, called vesicles, measure not less than $2.0 \mathrm{~mm}$ in at least one dimension the apparent specific gravity is between 1.0 and 2.0. Figure 1 shows the cinder used in study.

Tests conducted on Cinder were

Specific gravity $=1.52$
Bulk density in Loose state \% voids was $67.84 \%$ and Compacted state \% voids was $59.76 \%$;

Aggregate crushing test was $32.01 \%$

Water absorption was $8.8 \%$

Fineness modulus was found to be 7.414

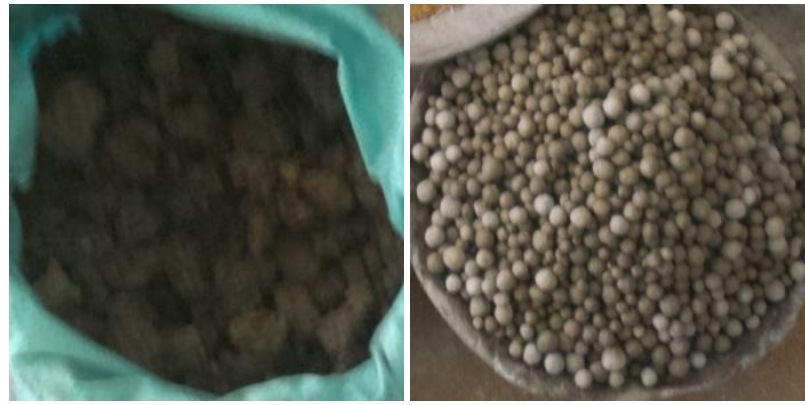

Fig. 1. Cinder \& LECA

LECA: It is abbreviated as LIGHT EXPANDED CLAY AGGREGATES. It is the special type of aggregate which are formed by pyroclastic process in rotary kiln at very high temperature. Since it is exposed to high temperature, the organic compounds burn, as a result the pellets expand $\&$ form a honeycombed structure. Whereas the outside surface of each granule melts and is sintered. The resulting ceramic pellets are lightweight, porous and have a high crushing resistance. It is environmental friendly, entirely a natural product incorporating same benefits as tile in brick form. LECA is non destructible, non combustible \& impervious to attack by dry-rot, wet-rot $\&$ insects. Figure 2 shows the LECA used in study.

Based on the standard tests the results were as Tests conducted on Leca were

Specific gravity $=0.51$

Bulk density in Loose state \% voids was $79.59 \%$ and Compacted state \% voids was $68.94 \%$

Aggregate crushing test was $37.52 \%$;

Water absorption was $16.42 \%$

Fineness modulus was found to be 6.448 .

TABLE I: MIX PROPORTIONS

\begin{tabular}{|l|l|l|}
\hline Sl.No & \multicolumn{2}{|c|}{ MIX PRPORTIONS of M30 LWC } \\
\hline 1 & Cement & $413 \mathrm{~kg} / \mathrm{m} 3$ \\
\hline 2 & Water & $186 \mathrm{~kg} / \mathrm{m} 3$ \\
\hline 3 & Fine Aggregats & $706 \mathrm{~kg} / \mathrm{m} 3$ \\
\hline 4 & Coarse Aggregates & 1117 \\
& (40\% Leca \& 60\% & $\mathrm{kg} / \mathrm{m} 3$ \\
& Cinder) & \\
\hline 5 & Water Cement Ratio & 0.45 \\
\hline
\end{tabular}

In present study Leca and cinder were selected as light weight aggregates and their properties were tested. Based on the characteristics, design mix was arrived on ISI method. These aggregates are blended in a defined proportion starting from $0 \%$ to $100 \%$ for replacement of natural coarse aggregates. For each replacement ratio specimen's cubes and cylinders were cast as shown in figure 3 . The elements were subjected to standard curing placing in water at ambient room temperature for 28 days The cured cube specimens was subjected to compressive loadings and the corresponding strength characteristics were determined as shown in figure 4 . 
The average compressive strength are tabulated in Table 2

TABle2. AVERAge CoMPREsSIVE STRENGTH

\begin{tabular}{|c|c|c|c|c|c|}
\hline \multirow{2}{*}{$\begin{array}{c}\text { SL } \\
\text { No }\end{array}$} & \multicolumn{2}{|c|}{ LWA } & \multirow{2}{*}{$\begin{array}{c}\text { Density } \\
\left(\mathbf{k g} / \mathbf{m m}^{3}\right)\end{array}$} & \multicolumn{2}{c|}{$\begin{array}{c}\text { Avg Compressive } \\
\text { Strength }\end{array}$} \\
\cline { 2 - 3 } \cline { 5 - 6 } & \% Leca & \% $\left.\mathbf{m m}^{2}\right)$ \\
\hline 1 & 0 & 100 & 2364.44 & 28.560 & 38.677 \\
\hline 2 & 10 & 90 & 2308.74 & 28.234 & 37.929 \\
\hline 3 & 20 & 80 & 2229.33 & 27.855 & 37.440 \\
\hline 4 & 30 & 70 & 2181.63 & 27.213 & 36.836 \\
\hline 5 & 40 & 60 & 1909.63 & 26.110 & 36.525 \\
\hline 6 & 50 & 50 & 1837.04 & 23.223 & 30.399 \\
\hline 7 & 60 & 40 & 1773.33 & 22.169 & 27.265 \\
\hline 8 & 70 & 30 & 1690.00 & 21.145 & 26.220 \\
\hline 9 & 80 & 20 & 1636.15 & 20.464 & 25.142 \\
\hline 10 & 90 & 10 & 1541.63 & 19.892 & 24.491 \\
\hline 11 & 100 & 0 & 1506.37 & 19.235 & 23.202 \\
\hline
\end{tabular}

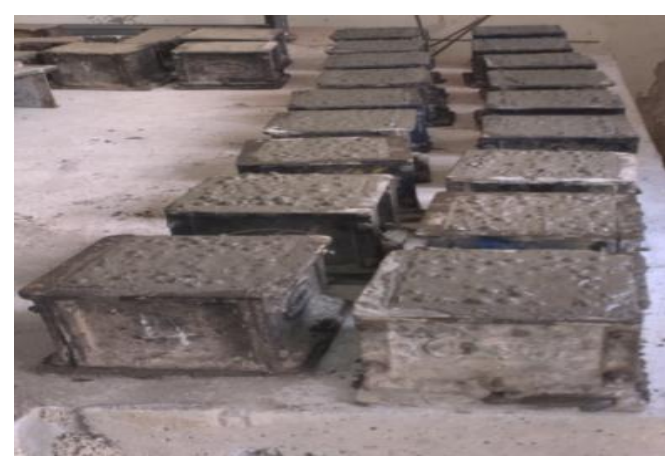

Fig. 3. Casted cubes

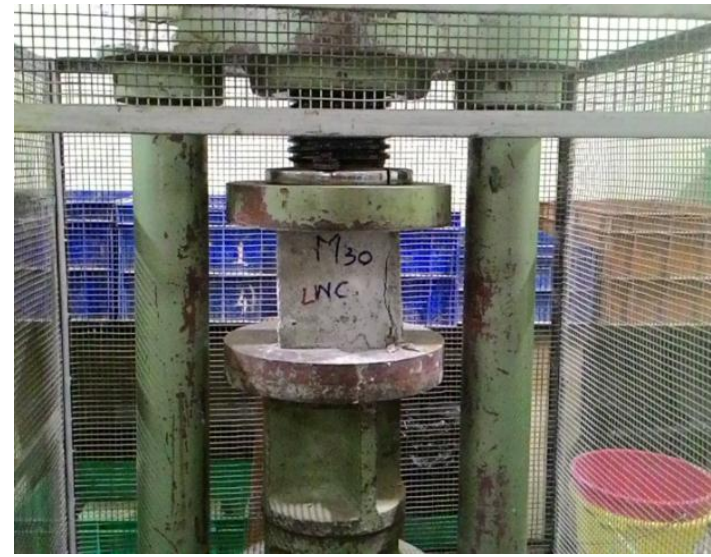

Fig. 4. Testing of cubes

Table3. Average Tensile StRength

\begin{tabular}{|c|c|c|c|c|c|}
\hline \multirow{2}{*}{$\begin{array}{c}\text { SL } \\
\text { No }\end{array}$} & \multicolumn{2}{|c|}{ LWA } & \multirow{2}{*}{$\begin{array}{c}\text { Slump } \\
\text { in mm }\end{array}$} & \multicolumn{2}{c|}{$\begin{array}{c}\text { Avg Tensile Strength } \\
\left(\mathbf{N} / \mathbf{m m}^{2}\right)\end{array}$} \\
\cline { 2 - 3 } \cline { 5 - 6 } & $\begin{array}{c}\% \\
\text { Leca }\end{array}$ & \%Cinder & & 7 days & $\mathbf{2 8}$ days \\
\hline 1 & 0 & 100 & 27 & 1.915 & 2.698 \\
\hline 2 & 10 & 90 & 32 & 1.874 & 2.686 \\
\hline 3 & 20 & 80 & 34 & 1.861 & 2.659 \\
\hline 4 & 30 & 70 & 49 & 1.788 & 2.562 \\
\hline 5 & 40 & 60 & 56 & 1.710 & 2.500 \\
\hline 6 & 50 & 50 & 54 & 1.556 & 2.125 \\
\hline 7 & 60 & 40 & 51 & 1.432 & 1.903 \\
\hline 8 & 70 & 30 & 48 & 1.210 & 1.686 \\
\hline 9 & 80 & 20 & 41 & 0.975 & 1.472 \\
\hline 10 & 90 & 10 & 38 & 0.854 & 1.223 \\
\hline 11 & 100 & 0 & 36 & 0.836 & 1.187 \\
\hline
\end{tabular}

\section{RESULTS \& DISCUSSIONS}

The comparison of experimental results and analyzing were done in graphical way.

Analysis of slump results of fresh concrete mix: Here the slump test carried out for various proportions of fresh concrete mixes of M30 grade are compared.

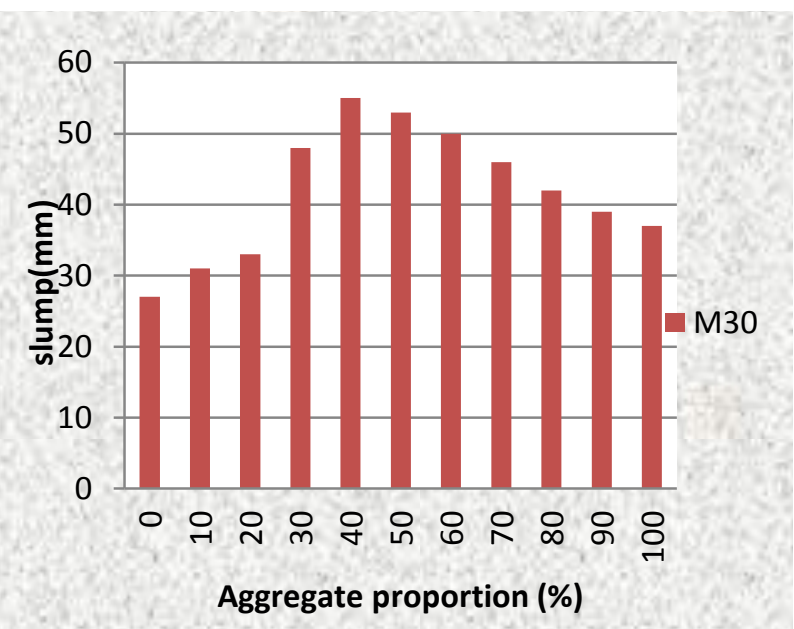

Fig. 5. Comparison of \%Aggregate proportion V/S Slump

Analysis of compressive and tensile strength of hardened concrete: The compressive strength and tensile strength of various proportions of M30 for different curing periods such as 7 days and 28 days are analyzed

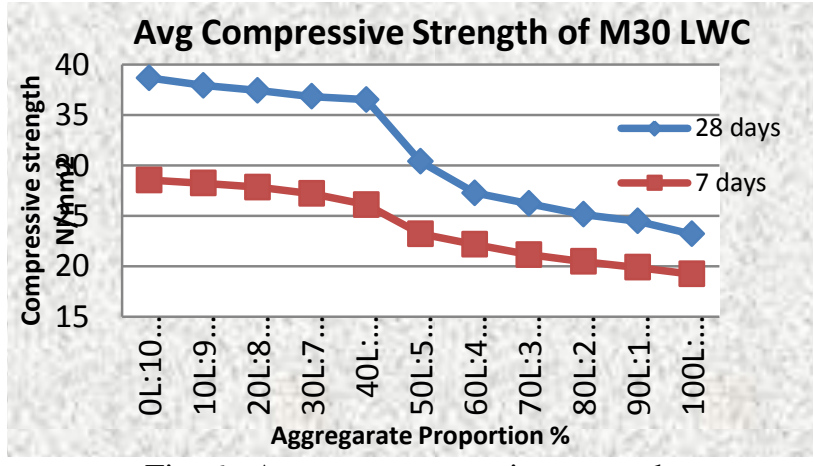

Fig. 6. Average compressive strength

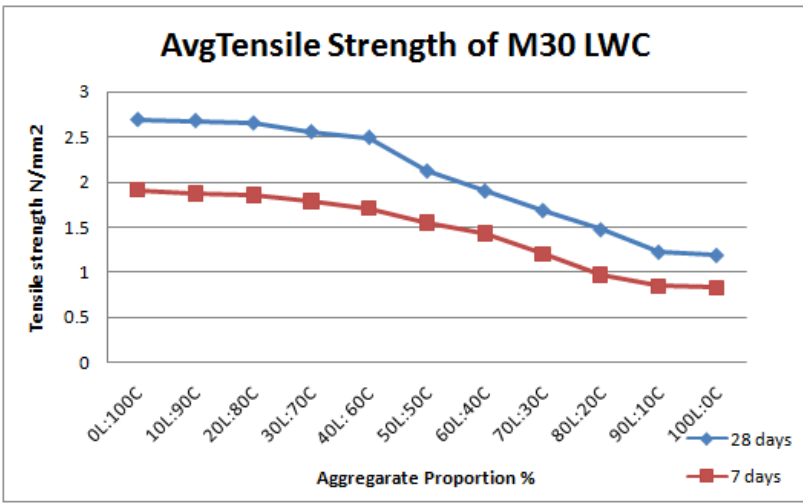

Fig. 7. Average tensile strength

Replacing normal aggregate by $60 \%$ of Cinder \& $40 \%$ has found to be optimum design mix for obtaining the designed concrete mix which can be seen in the experimental results. In order to improve the compressive strength, for the same mix the $20 \%$ of cement was 
replaced by Ground Granulated Blast Furnace Slag (GGBFS) which enhanced the compressive strength from $36.52 \mathrm{~N} / \mathrm{mm}^{2}$ to $39.20 \mathrm{~N} / \mathrm{mm}^{2}$. The mix proportions and results are tabulated in Table 4 and 5 respectively.

TABLE 4: MiX PROPORTIONS FOR M30 GRADE OF LIGHT WEIGHT CONCRETE WITH 20\%GGBFS

\begin{tabular}{|l|c|c|}
\hline 1 & Cement & $330.4 \mathrm{~kg} / \mathrm{m} 3$ \\
\hline 2 & GGBFS & $82.6 \mathrm{~kg} / \mathrm{m} 3$ \\
\hline 3 & Water & $186 \mathrm{~kg} / \mathrm{m} 3$ \\
\hline 4 & Fine aggregates & $706 \mathrm{~kg} / \mathrm{m} 3$ \\
\hline 5 & Coarse aggregates & $1117 \mathrm{~kg} / \mathrm{m} 3$ \\
\hline 6 & Water cement ratio & 0.45 \\
\hline
\end{tabular}

TABLE 5: COMPRESSIVE STRENGTH OF M30 GRADE OF NORMAL AGGREGATES CONCRETE \& LWC WITH $60 \%$ CINDER, 40\% LECA AS AGGREGATES WITH 20\% GGBFS

\begin{tabular}{|c|c|c|c|}
\hline $\begin{array}{c}\text { Compressive Strength } \\
\text { of Normal Concrete } \\
\text { (N/mm2) }\end{array}$ & $\begin{array}{c}\text { Compressive Strength of } \\
\text { Light weight concrete } \\
\text { (N/mm2) }\end{array}$ \\
\hline 7days & 28days & 7days & 28days \\
\hline 31.89 & 43.53 & 27.12 & 39.20 \\
\hline 31.63 & 43.26 & 27.30 & 39.47 \\
\hline 31.72 & 43.42 & 27.09 & 38.93 \\
\hline
\end{tabular}

\section{IV.CONCLUSION}

The experimental investigation carried out and in scope of work carried out, the following conclusions are drawn out:

- Normal coarse aggregate can be replaced by using Cinder and Leca.

- Increasing the percentage of light weight aggregate decreases the cubes weight from $8.9 \mathrm{~kg}$ to $6.45 \mathrm{~kg}$. But simultaneously there was decreasing strength. Blending of light weight aggregates showed better performance in this case

- The concrete mixes are blended in various proportions like $(50 ; 50,60 ; 40,70 ; 30,80 ; 20,90 ; 10$,fully $100 \%)$ vice versa in Leca \& Cinder.

- $60 \%$ of cinder and $40 \%$ of LECA with $20 \%$ of GGBS replaced for cement gave a good low weight structural concrete.

- Cinder and LECA can be used as light weight aggregate in replacement of normal coarse aggregate. M30 grade light weight concrete had an average compressive strength of $39.20 \mathrm{~N} / \mathrm{mm}^{2}$ respectively which was almost nearer to the compressive strength of normal aggregate concrete which was $43.40 \mathrm{~N} / \mathrm{mm}^{2}$.

- The density of light weight aggregate concrete varied from 1800 to $1950 \mathrm{~kg} / \mathrm{mm}^{3}$ which were lesser than that of normal weight concrete having a density of 2637 $\mathrm{kg} / \mathrm{mm}^{3}$.

- There was significant cost reduction when compared to normal concrete. The batching of concrete work is done in volume wise, $1 \mathrm{~kg}$ of LECA replaced $3.5 \mathrm{~kg}$ of normal aggregate by mass.

\section{REFERENCES}

[1] K. Dhir, R. G. C.Mays, and H. C. Chua, 1984, Lightweight Structural Concrete with Aglite aggregate: mix design and properties, International Journal of Cement Composites and Lightweight Concrete, Vol 6, (4) Nov. 1984, 249-260
[2] H Ceilikozyildirium, 2000, Laboratory Investigation on Mechanical properties of Light Weight Aggregate Concrete, Euro Lightcon, Economic Design And Constructive With Light Weight Aggregate Concrete Document, BE96-3942/R23, June 2000

[3] W GMoravia , C.A.S Oliveria , A.G Gumieri , W.L Vasconcelos , 2006, Micro Structural Evaluation Of Expanded Clay To Be Used The Aggregate In Structural Concrete, Ceramics Vol.52 June 2006

[4] Fahrizalzulkarnain, Mahyuddinramli, 2008, Durability Of Light Weight Aggregate Concrete For Housing Construction, 2nd International Conference on Built Environment In Developing Countries (ICBEDC 2008)

[5] Mouli M, Khelafi H, 2008, Performance Characterizes Of Lightweight Aggregate Concrete Containing Natural Pozzolan, Build. Environ. Vol 43, 31-36

[6] Khandaker M. Anwar Hossain , 2008, Blended Cement And Light Weight Concrete Using Scoria :Mix Design, Strength, Durability And Heat Insulation Characteristics, International Journal of Physical Sciences, Sept 2008

[7] 10262 (2009): Guidelines for concrete mix design proportioning

[8] V. Khonsari, E. Eslami \& Ah. Anvari, 2010, Effects of expanded perlite aggregate on the mechanical behavior of light weight concrete, Proceedings of Fracture Mechanics of Concrete and Concrete Structures, March 2010, 1354-1361

[9] Ling I H ,Teo D.C.L, 2012, Compressive Strength Of And Durability Property Of Light Weight Concrete, International Journal Of Sustainable Energy Development, Volume 1, Dec 2012

[10] Jihad Hamad Mohammed, Ali Jihad Hamad, 2014, A Classification Of Lightweight Concrete: Materials, Properties And Application Review, International Journal of Advanced Engineering Applications, Vol.7, Iss.1, 2014, 52-57

[11] Alireza Motamednia, Vahid Nasiri, Rasoul Jani, 2013, Laboratory Investigation On Light Weight Concrete Against Acids, Research Journal Of Chemical And Environmental Studies, Volume 1, Aug 2013

[12] S. Sivakumar And B. Kameshwari, 2015, Influence Of Flyash , Bottom ash and Light Expanded Clay Aggregate On Concrete, Advances In Material Science And Engineering

[13] Raymond T, Hemmings , Bruce J ,Cornelius, 2009, Comparative Study Of Light Weight Aggregates, World Of Coal Ash Conference, May 2009

[14] Dr. V Bhaskar Desai , Mr. A Satyam, 2014, Some Studies On Strength Properties Of Light Weight Concrete, International Journal Of Scientific And Research Publications, Volume 4, Feb 2014

\section{BIOGRAPHY}

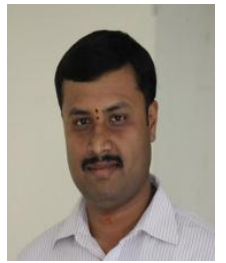

Name: Mr. ANIL KUMAR.R

Qualification: B.E., M.Tech in Structural Engineering, (Ph.D) Designation: Assistant Professor Department: Civil Engineering College: M.S.Ramaiah Institute of Technology, Mathikere, Bangalore-54 